\title{
A Comparative Study on the Polyphenolic Content, Antibacterial Activity and Antioxidant Capacity of Different Solvent Extracts of Brassica Oleracea Vegetables
}

\author{
Amit Jaiswal \\ Technological University Dublin, amit.jaiswal@tudublin.ie \\ Nissreen Abu-Ghannam \\ Technological University Dublin, nissreen.abughannam@tudublin.ie \\ Shilpi Gupta \\ Technological University Dublin, shilpi.19may@gmail.com
}

Follow this and additional works at: https://arrow.tudublin.ie/schfsehart

Part of the Microbiology Commons

\section{Recommended Citation}

Jaiswal, A. K., Abu-Ghannam, N. \& Gupta, S. (2012). A comparative study on the polyphenolic content, antibacterial activity and antioxidant capacity of different solvent extracts of Brassica oleracia vegetables. International Journal of Food Science \& Technology, 47(2), 223-231. doi:10.1111/ j.1365-2621.2011.02829.x

This Article is brought to you for free and open access by the School of Food Science and Environmental Health at ARROW@TU Dublin. It has been accepted for inclusion in Articles by an authorized administrator of ARROW@TU

Dublin. For more information, please contact arrow.admin@tudublin.ie, aisling.coyne@tudublin.ie, gerard.connolly@tudublin.ie.

Funder: Irish Government under the Technological Sector Research Scheme (Strand III) of the National Development Plan

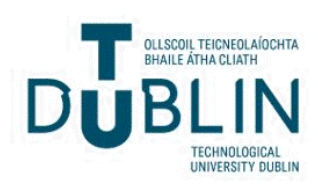




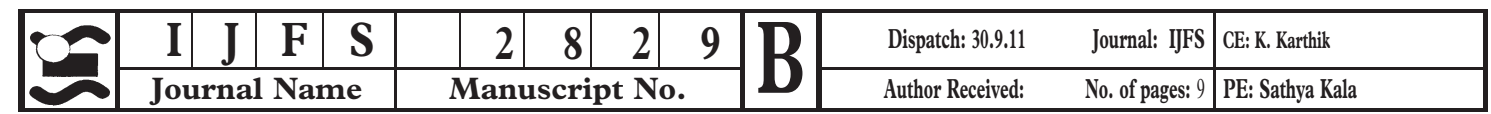

\title{
A comparative study on the polyphenolic content, antibacterial activity and antioxidant capacity of different solvent extracts of 1 Brassica oleracea vegetables
}

\author{
Amit K. Jaiswal, Nissreen Abu-Ghannam* \& Shilpi Gupta \\ School of Food Science and Environmental Health, College of Sciences and Health, Dublin Institute of Technology, Cathal Brugha Street, Dublin 1, \\ Ireland
}

(Received 22 May 2011; Accepted in revised form 14 September 2011)

\begin{abstract}
Summary Brassica vegetables are rich in polyphenols, flavonoids and glucosinolates. Investigation was undertaken to optimise the best solvents among $60 \%$ ethanol, acetone and methanol for the extraction of polyphenols from Brassica vegetables. Furthermore, different properties such as antibacterial activity and antioxidant capacity were also investigated. Results showed that a $60 \%$ methanolic extract showed the highest total phenolic content which was 23.6, 20.4 and $18.7 \mathrm{mg}$ gallic acid equivalents (GAE) $\mathrm{g}^{-1}$ extract for broccoli, Brussels sprouts and white cabbage, respectively. The hydroxybenzoic acid content of various solvent extracts ranged from 5.86 to $8.91 \mathrm{GAE} \mathrm{g}^{-1}$ extract for broccoli, 2.70 to $5.44 \mathrm{GAE} \mathrm{g}^{-1}$ extract for Brussels sprouts and 3.69 to $4.86 \mathrm{GAE} \mathrm{g}^{-1}$ extract for white cabbage, while the hydroxycinnamic acid content ranged from 0.78 to 1.26 chlorogenic acid equivalents (CAE) g $\mathrm{g}^{-1}$ extract for broccoli, 1.41 to $3.45 \mathrm{CAE} \mathrm{g}^{-1}$ extract for Brussels sprouts and 0.49 to $1.14 \mathrm{CAE} \mathrm{g}^{-1}$ extract for white cabbage. A concentrationdependent antioxidative capacity was confirmed for different reactive oxygen species, and moderate antibacterial activity was observed against a number of Gram-negative and Gram-positive food spoilage and food pathogenic bacteria. Solvents significantly affected polyphenolic content and its different properties, and the methanol was found to be the best solvent for the extraction of polyphenols from studied Brassica vegetables.
\end{abstract}

Keywords Antibacterial activity, antioxidant capacity, Brassica vegetables, high-performance liquid chromatography, organic solvent, polyphenols.

\section{Introduction}

Polyphenols (PPs) are a large and diverse class of compounds, many of which occur naturally in a range of plants characterised by the presence of several phenolic groups (i.e. aromatic rings with hydroxyls). Naturally occurring PPs can be broadly divided into phenolic acids and flavonoids. The phenolic acids can be further categorised into derivatives of benzoic acid and cinnamic acid (Clifford, 2000). Flavonoids include flavonols (e.g. quercetin and kaempferol, the most ubiquitous flavonoids in foods), flavones, isoflavones, flavanones, anthocyanidins, flavanols (catechins-monomers and proanthocyanidin-polymers, or condensed tannins; March \& Brodbelt, 2008). The hydroxyl groups of PPs

*Correspondent: Fax: +3531878 8978;

e-mail: nissreen.abughannam@dit.ie are very reactive in neutralising free radicals by donating a hydrogen atom or an electron, chelating metal ions, inactivating lipid-free radical chains and preventing hydroperoxide conversions into reactive oxyradicals (Bravo, 1998).

All aerobic organisms, including human beings, have antioxidant defences that protect against oxidative injuries and numerous damage removal, and the repair enzymes are present to remove or repair disabled molecules (Ali et al., 2001). However, this natural antioxidant mechanism can be inefficient; hence, dietary intake of antioxidant compounds becomes important (Halliwell, 1994). Antioxidants have been also applied in the food industry to prolong the shelf life of foods, especially those rich in lipids containing polyunsaturated fatty acids because these fatty acids are readily oxidised by molecular oxygen. Synthetic antioxidant compounds, such as butylated hydroxytoluene (BHT) and butylated 
hydroxyanisole (BHA), have been commonly used in processed foods to control lipid oxidation.

There are also increasing concerns about food safety owing to the rising bacterial contamination of foods, which is known to be responsible for spoilage and transmission of food-borne disease. The problem of food-borne disease is particularly acute in ready-to-eat foods and dairy products, which are not normally reheated prior to ingestion. Pasteurisation and cooking are satisfactory methods, which guarantee that viable cells are removed but heat treatment is not desirable for all types of food products, so prevention of pathogenic and spoilage microorganisms in foods is usually achieved by chemical preservatives. It is reported that synthetic chemicals which are used in food such as BHA and BHT have some side effects, including carcinogenesis (Botterweck et al., 2000). As a result, a great deal of effort has been directed towards identifying low-cost natural products that can replace synthetic chemicals.

Organic solvents are commonly used for the extraction of PPs from plant material. The most important factor that determines the recovery of PPs from plant material is the solubility of the phenolic compounds in the solvent used for the extraction process. Ethanol, methanol and acetone and their aqueous mixtures are commonly used for the extraction purposes. Zhou \& Yu (2006) used 50\% acetone/water as an extraction solvent for the extraction of PPs from Colorado-grown vegeta2 bles. Absolute methanol was used by Abas et al. (2006) and Wijngaard et al. (2009) for the extraction of phenolic antioxidants from leafy vegetables and Irish fruits and vegetables waste, respectively, whereas Sreeramulu \& Raghunath (2010) used $60 \%$ methanol with $0.1 \% \mathrm{HCl}$ for the extraction of PPs from vegetables and tubers.

Brassica oleracea belongs to the Brassicaceae or Cruciferae family comprised of approximately 3500 described species apportioned among 350 genera including cauliflower, broccoli, kohlrabi, kale, cabbage and Brussels sprouts. Numerous studies have highlighted the potential importance of Brassica vegetables as a source of antibacterial (Kyung \& Fleming, 1994; Hu et al., 2004; Ayaz et al., 2008) and antioxidant substance (Zhou \& Yu, 2006; Andarwulan et al., 2010; Isabelle et al., 2010).

The main objective of this study is to optimise the best solvents among 60\% methanol, ethanol and acetone for the extraction of PPs from Brassica oleracea vegetables. Furthermore, different properties such as antibacterial activity and antioxidant capacity were also investigated. These objectives are justified having in mind that the literature lacks some information on solvent optimisation for the extraction of PPs from Brassica vegetables, particularly Brassica oleracea species. Besides, the effect of solvent on different group of PPs, antioxidant and antibacterial properties has not been widely explored.

\section{Materials and methods}

\section{Chemicals}

All the chemicals and reference compounds were purchased from Sigma-Aldrich Chemical Co. (Steinheim, Germany).

\section{Plant material and their preparation}

Fresh, Irish Brassica vegetables such as white cabbage, broccoli and Brussels sprouts were purchased once in a lot of $10-15 \mathrm{~kg}$ for each vegetable. Vegetables were selected randomly from a local supermarket (Dunnes Store) in Dublin in December 2009. For the cabbage, immediately after purchase, outer leaves were removed and heads were then divided into four segments, and the central core was removed. The segments were chopped into $0.5 \times 5-6 \mathrm{~cm}$ pieces, using a vegetable-cutting machine. For Brussels sprouts, external leaves and $2 \mathrm{~mm}$ of the lower ends were removed, and the whole sprouts were used for the analysis, whereas in the case of broccoli, the heads were obtained by cutting the main stalk. The florets, together with about $1 \mathrm{~cm}$ of the stalk, were cut off from the rest of the stalk and were used as broccoli samples. Finally, the above prepared samples were crushed with the help of motor and pestle in the presence of liquid nitrogen and stored at $-20^{\circ} \mathrm{C}$ until used.

\section{Preparation of extracts}

A $5 \mathrm{~g}$ of crushed vegetable samples was added to three different flasks and extracted using 60\% methanol, $60 \%$ ethanol or $60 \%$ acetone with $1-\mathrm{min}$ nitrogen flushing at $20 \mathrm{psi}$. The concentration of solvent was decided on the basis of available literature (Zhao \& Hall, 2008; Cox et al., 2010). Flasks were kept in a shaking incubator (Innova 42, Mason Technology, Dublin, Ireland) at $100 \mathrm{rpm}$ and $40^{\circ} \mathrm{C}$ for $2 \mathrm{~h}$. The infusions were filtered with Whatman \#1 until a clear extract was obtained. The extracts were evaporated to dryness in a multievaporator (Syncore Polyvap, Mason Technology, Dublin, Ireland) at $60^{\circ} \mathrm{C}$ at their respective pressure and stored at $-20^{\circ} \mathrm{C}$ until used.

\section{Phytochemical analysis}

\section{Determination of total polyphenolic content}

Total polyphenolic content (TPC) of vegetable extracts was determined by the method of (Ganesan et al., 2008), using Folin-Ciocalteau's phenol reagent. Results were expressed as gallic acid equivalents per gram $\left(\mathrm{GAE} \mathrm{g}^{-1}\right)$ of dried weight (dw) of extract through the calibration curve of gallic acid. 
High-performance liquid chromatography coupled with diode array detector analysis of polyphenolic compounds

The high-performance liquid chromatography coupled with diode array detector (HPLC-DAD) analysis of polyphenolic compounds of vegetable extracts was measured according to the existing method in our laboratory (Jaiswal et al., 2011a). In brief, the HPLC system consisted of a reversed-phase HPLC column on an Alliance HPLC (e2695 Separations modules; Waters, Milford, MA, USA) equipped with an autosampler and controller with dual pump, a 2998 photodiode array detector and the Empower software. An Atlantis C18 column $(250 \times 4.6 \mathrm{~mm}, 5-\mu \mathrm{m}$ particle size $)$ from Waters (Waters) was used for polyphenolic separation at $25^{\circ} \mathrm{C}$. Mobile phase used was similar to as reported in our earlier study (Jaiswal et al., 2011a). The chromatograms were monitored at $280 \mathrm{~nm}$ [hydroxybenzoic acid (HBA)], $320 \mathrm{~nm}$ [hydroxycinnamic acid (HCA)], $360 \mathrm{~nm}$ (flavones and flavonols) and $520 \mathrm{~nm}$ (anthocyanins); complete spectral data were recorded in the range of $220-600 \mathrm{~nm}$.

\section{Determination of total flavonoid content}

The total flavonoid content (TFC) was determined according to the method of Liu et al. (2009), and the results were expressed as quercetin equivalents per gram $\left(\mathrm{QE} \mathrm{g}^{-1}\right)$ of $(\mathrm{dw})$ of extract.

\section{Antioxidant capacity analysis}

In this study, five different methods [2,2-diphenyl1-picrylhydrazyl (DPPH)-free radical scavenging capacity, ferric ion reducing antioxidant potential (FRAP) assay, lipid peroxidation (LPO) in a haemoglobin-induced linoleic acid system, ferrous ion-chelating capacity (FIC) and hydrogen peroxide $\left(\mathrm{H}_{2} \mathrm{O}_{2}\right)$-scavenging assay] were used for the estimation of total antioxidant capacity of the Brassica vegetables. All the methods were carried out according to the existing protocols in our laboratory (Rajauria et al., 2010). For the DPPH free radical-scavenging capacity and LPO inhibitory ability, ascorbic acid was used as a reference compound and the results were expressed as $\mathrm{mg}$ ascorbic acid equivalents per gram (AscE $\left.g^{-1} ; \mathrm{dw}\right)$ of extract. Trolox was used as a standard for FRAP assay, and the results were expressed as $\mathrm{mg}$ trolox equivalents per gram $\left(\mathrm{TE} \mathrm{g}^{-1}\right.$; dw) of extract; BHT was used as a reference compound for $\mathrm{H}_{2} \mathrm{O}_{2}$-scavenging capacity, and the results were expressed as mg butylated hydroxytoluene equivalents per gram (BHTE g $\mathrm{g}^{-1} \mathrm{dw}$ ) of extract whereas ethylenediaminetetraacetic acid (EDTA) was used as a reference compound for FIC, and the results were expressed as mg EDTA equivalents per gram (BHTE $\mathrm{g}^{-1} ; \mathrm{dw}$ ) of extract.

\section{Antibacterial activity}

Bacterial strains and growth conditions

The bacterial strains used in this study were Gramnegative (Salmonella abony NCTC 6017, Pseudomonas aeruginosa ATCC 27853) and Gram-positive (Listeria monocytogenes ATCC 19115, Enterococcus faecalis ATCC 7080; Medical Supply Company, Dublin, Ireland). All the cultures were maintained at $-70{ }^{\circ} \mathrm{C}$ in $20 \%$ glycerol stocks and grown in Tryptic Soy Broth (TSB, pH 7.2; Scharlau Chemie, Barcelona, Spain) at $37^{\circ} \mathrm{C}$ except $P$. aeruginosa, which was grown at $30^{\circ} \mathrm{C}$ for $18 \mathrm{~h}$ to obtain subcultures. To achieve a working concentration, a bacterial suspension was prepared in $\mathrm{NaCl}, 0.85 \%$ (BioMerieux, Marcy l'Etoile, France) equivalent to McFarland standard of 0.5 with the help of Densimat photometer (BioMerieux). Finally, the suspension was diluted with TSB to achieve a concentration of $1 \times 10^{6} \mathrm{cfu} \mathrm{mL}^{-1}$.

\section{Antibacterial activity assay}

The antibacterial activity of vegetable extracts was measured according to the existing method in our laboratory (Jaiswal et al., 2011b) using sterile, roundbottomed 96-well microtitre plates. Sodium benzoate (SB) and sodium nitrite (SN) were taken as positive controls.

\section{Statistical analysis}

Extraction of phytochemicals and estimation of TPC and TFC of extracts were carried out in triplicates whereas all the antioxidant analysis were carried out in triplicate and repeated twice. HPLC-DAD analysis of PPs was carried out in duplicates. Results are expressed as mean values \pm standard deviation. Analysis of variance (ANOVA) and multiple comparisons (Fisher's least-significant-difference test) were used to evaluate the significant difference among various treatments using the statgraphics Centurion XV. Differences at $\mathbf{3}$ $P<0.05$ were considered to be significant.

\section{Results and discussion}

\section{Extraction yield, total phenol and flavonoid content}

For the selection of proper organic solvents for PPs extraction from Brassica vegetables, different organic solvents such as $60 \%$ methanol, ethanol or acetone were examined. The yields of the different solvent extract of the studied vegetables are shown in Table 1. The extraction yield of methanolic extract from broccoli was 1.4 times higher than those of ethanol and acetone extracts, respectively, while no significant difference $(P>0.05)$ was observed between ethanol and acetone 
Table 1 Total phenol, flavonoid, HBAs, HCAs, PMF content and extraction yield of Irish Brassica vegetables (broccoli, Brussels sprouts and white cabbage) obtained from different solvent systems

\begin{tabular}{|c|c|c|c|c|c|c|}
\hline Extraction solvent & $\begin{array}{l}\text { Extraction } \\
\text { yield* }(\%)\end{array}$ & $\begin{array}{l}\text { TPC* GAE } g^{-1} \\
(d w) \text { of extract }\end{array}$ & $\begin{array}{l}\text { TFC* QE } g^{-1} \\
\text { (dw) of extract }\end{array}$ & $\begin{array}{l}\mathrm{HBA}^{* *} \mathrm{GAE} \mathrm{g}^{-1} \\
(\mathrm{dw}) \text { of extract }\end{array}$ & $\begin{array}{l}\mathrm{HCA}^{* *} \mathrm{CAE} \mathrm{g}^{-1} \\
(\mathrm{dw}) \text { of extract }\end{array}$ & $\begin{array}{l}\mathrm{PMF}^{* *} \mathrm{RE} \mathrm{g}^{-1} \\
(\mathrm{dw}) \text { of extract }\end{array}$ \\
\hline \multicolumn{7}{|l|}{ Broccoli } \\
\hline $60 \%$ Methanol & $5.25 \pm 0.22^{a}$ & $23.6 \pm 1.75^{a}$ & $17.5 \pm 1.25^{a}$ & $8.15 \pm 0.02^{a}$ & $1.26 \pm 0.01^{a}$ & $1.40 \pm 0.68^{a}$ \\
\hline $60 \%$ Ethanol & $3.83 \pm 0.16^{b}$ & $19.4 \pm 1.09^{b}$ & $13.8 \pm 1.12^{\mathrm{b}}$ & $8.91 \pm 0.05^{b}$ & $0.49 \pm 0.01^{b}$ & $0.92 \pm 0.02^{b}$ \\
\hline $60 \%$ Acetone & $3.81 \pm 0.10^{b}$ & $17.9 \pm 2.14^{\mathrm{c}}$ & $12.5 \pm 1.11^{b}$ & $5.86 \pm 1.33^{c}$ & $0.78 \pm 0.01^{\mathrm{c}}$ & $0.84 \pm 0.01^{b}$ \\
\hline \multicolumn{7}{|l|}{ Brussels sprouts } \\
\hline $60 \%$ Ethanol & $6.82 \pm 0.14^{a}$ & $19.1 \pm 0.44^{\mathrm{b}}$ & $11.3 \pm 1.25^{b}$ & $5.44 \pm 0.21^{b}$ & $1.41 \pm 0.01^{\mathrm{b}}$ & $2.17 \pm 0.01^{b}$ \\
\hline $60 \%$ Acetone & $6.20 \pm 0.17^{b}$ & $18.12 \pm 2.24^{\mathrm{C}}$ & $12.1 \pm 2.60^{\mathrm{ab}}$ & $2.70 \pm 0.08^{c}$ & $2.29 \pm 0.02^{\mathrm{C}}$ & $2.62 \pm 0.49^{c}$ \\
\hline \multicolumn{7}{|l|}{ White cabbage } \\
\hline $60 \%$ Methanol & $5.08 \pm 0.05^{a}$ & $18.7 \pm 0.43^{a}$ & $8.80 \pm 1.25^{a}$ & $4.86 \pm 0.43^{a}$ & $1.13 \pm 0.01^{a}$ & ND \\
\hline $60 \%$ Ethanol & $4.69 \pm 0.09^{a b}$ & $16.38 \pm 0.67^{b}$ & $6.7 \pm 0.72^{b}$ & $4.78 \pm 0.01^{a}$ & $1.14 \pm 0.01^{a}$ & ND \\
\hline $60 \%$ Acetone & $4.45 \pm 0.07^{b}$ & $14.78 \pm 0.43^{c}$ & $4.12 \pm 0.72^{\mathrm{c}}$ & $3.69 \pm .35^{b}$ & $0.49 \pm 0.01^{b}$ & ND \\
\hline
\end{tabular}

*Data are expressed as mean $\pm \mathrm{SD}(n=3)$.

* Data are expressed as mean $\pm \mathrm{SD}(n=2)$.

TPC, total phenolic content; TFC, total flavonoid content; HBA, hydroxybenzoic acid; HCA, hydroxycinnamic acid; PMF, polymethoxylated flavones; dw, dried weight.

Means not sharing the same letter are significantly different (LSD) at $P<0.05$ probability level in each row for different solvent extracts of individual species.

extracts. Brussels sprouts methanol and ethanol extracts were 1.1 times higher than acetone extract, whereas no significant difference $(P>0.05)$ was observed between methanol and acetone extracts. A similar trend was also observed for white cabbage extracts. It was evident that extraction with methanol resulted in higher yield with a descending order of methanol $>$ ethanol $>$ acetone. These results were in agreement with the effects of solvent on total yield from buckwheat (Sun \& Ho, 2005) and barley seed extracts (Liu \& Yao, 2007).

Table 1 summarises the TPC of the different solvent extracts of fresh vegetables. Broccoli methanolic extract had 1.2 and 1.3 times higher TPC than those of ethanol and acetone extracts, respectively. Almost similar trends were observed for Brussels sprouts and white cabbage. The results indicated that methanol was superior to ethanol and acetone in extracting PPs, which agrees with results obtained from the microalga (Rao et al., 2006) and seaweeds (Cox et al., 2010). Among the studied solvents methanolic extract exhibited significantly $(P<0.05)$ higher TPC for all the vegetables, while among vegetables broccoli had the highest phenolic content followed by Brussels sprouts and white cabbage. This implies that the phenolic compounds in the Brassica vegetables might be readily soluble in methanol and more sparingly soluble in ethanol and acetone.

Results from this study showed that Irish Brassica vegetables had phenolic content well within the range reported by other authors (Kim et al., 2004; Podsędek et al., 2006; Podsedek, 2007). In the present study, the TPC of different vegetables estimated were 140.6, 126.8 and $86.4 \mathrm{mg}$ per $100 \mathrm{~g}$ fresh weight (fw) for Brussels sprouts, broccoli and white cabbage, correspondingly. Podsędek (2007) reported that phenolic content in Brassica vegetables ranged from $15.3 \mathrm{mg}$ per $100 \mathrm{~g}$ (fw) in white cabbage to $337.0 \mathrm{mg}$ per $100 \mathrm{~g}$ (fw) in broccoli. Kim et al. (2004) reported that TPC of cabbage ranged from 110.2 to $153.3 \mathrm{mg}$ per $100 \mathrm{~g}$ (fw) while Podsedek et al. (2006) reported that TPC varied from 133.4 to $140.13 \mathrm{mg}$ per $100 \mathrm{~g}$ (fw) for Brussels sprouts.

In the case of TFC, variations observed among the solvents applied with respect to flavonoid extractability, but in all the cases methanolic extracts showed significantly $(P<0.05)$ higher TFC for all the vegetables (Table 1). Broccoli methanolic extract had 1.3 and 1.4 times higher TFC than those of ethanol and acetone extracts, respectively. Similarly, in Brussels sprouts, methanolic extract was 1.3 times higher than those of ethanol and acetone extracts, whereas in the case of white cabbage, it was 1.3 and 2.1 times higher than ethanol and acetone extracts, respectively. Among the studied vegetables, broccoli had the highest amount of TFC followed by Brussels sprouts, and the lowest was white cabbage. Andarwulan et al. (2010) studied the flavonoid content of 11 vegetables from west Java, Indonesia and found that it varied from 0.3 to $143 \mathrm{mg}$ per $100 \mathrm{~g}$ (fw), whereas Lin \& Tang (2007) reported 4.1 to $133.1 \mathrm{mg}$ QE per $100 \mathrm{~g}$ (fw). The flavonoid content found in this study was $106.2 \mathrm{mg}$ per $100 \mathrm{~g}$ (fw) for Brussels sprouts, $94.02 \mathrm{mg}$ per $100 \mathrm{~g}$ (fw) for broccoli and $41.1 \mathrm{mg}$ per $100 \mathrm{~g}$ (fw) for white cabbage which corresponded well with those determined by other authors. 
High-performance liquid chromatography coupled with diode array detector quantitative analysis of polyphenols

The HPLC-DAD recorded UV-vis spectrum of each peak of the chromatogram which allowed explicit attribution of each chromatographic peak to distinct class of PPs as each class exhibits a characteristic UVvis spectrum. Different groups of PPs were identified by comparing their UV-vis spectra with spectra of reference compounds and reported values. Polyphenolic profiles at $280 \mathrm{~nm}$ for the studied Brassica vegetables are presented in Fig. 1.

\section{Hydroxybenzoic acid derivatives}

Hydroxybenzoic acid derivatives are major class of phenolic acid characterised by the presence of a carboxyl group substituted on a phenol and have a general structure of $\mathrm{C} 6-\mathrm{C} 1$ derived directly from benzoic acid. HBA derivatives commonly occuring in plants include p-hydroxybenzoic acid, gallic acid, protocatechuic acid, salicylic acid and vanillic acid. HBA derivatives (range 255-280 nm) were quantified at $280 \mathrm{~nm}$ and expressed as gallic acid equivalents (GAE g ${ }^{-1}$; dw) extract. The concentration of HBA derivatives in different Brassica vegetables is presented in Table 1. The HPLC-DAD analysis showed that broccoli contains a mixture of three groups of phenolic compounds and that the predominating compound belongs to HBA derivatives (Fig. 1a). It was also evident that the recovery of individual phenolic compounds was dependent on the solvent used for the extraction. A $60 \%$ ethanolic broccoli extract showed the highest content of HBA, which was 1.1 and 1.5 times higher than methanol and acetone extract, respectively. A similar trend was observed in Brussels sprouts wherein three different groups of PPs were identified with HBA derivatives being the predominating category (Fig. 1b). From the chromatogram (Fig. 1c), it was evident that white cabbage was a mixture of only two groups of phenolic compounds namely HBA and HCA. There was no significant difference observed in the concentration of HBA for ethanol and methanol extracts, whereas acetone extract showed slightly lower content of the same.

\section{Hydroxycinnamic acid derivatives}

The HCA derivatives are the second major class of phenolic acid and more common than the HBA with a C6-C3 skeleton. The most widely distributed HCA derivatives are cinnamic, $p$-coumaric, caffeic, ferulic and sinapic acids. The HCA derivatives (range, 310-326 nm) were identified at $320 \mathrm{~nm}$ and expressed as chlorogenic acid equivalents ( $\mathrm{CAE} \mathrm{g}^{-1}$; dw) extract. The concentration of HCA in different Brassica vegetables is presented in Table 1. Results showed that like other phytochemicals, extraction of HCA derivatives also depended upon the extraction solvent. In the case of broccoli methanolic extract, HCA content was 2.6 and 1.6 times higher than those observed in ethanol and acetone extracts, respectively. Similar trends were also shown by different extracts of Brussels sprouts, whereas white cabbage showed no significant difference between methanol and ethanol extracts while acetone extract was 2.3 times lower than methanol and ethanol.

\section{Flavonoid derivatives}

Flavonoids are a major group of PPs, which possess a basic C15 phenyl-benzopyrone skeleton modified with differing numbers and positions of substituents, including hydroxyl, methoxyl and glycosyl groups. Flavonoid derivatives such as flavones [(range: 339-350 (band I) and 261-279 nm (band II)], polymethoxylated flavones (PMF; range: $324-336 \mathrm{~nm}$ ), glycosylated flavonoid (GSF) [(range: 347-370 nm (band I) and 250-267 nm (band II)] quantified at $360 \mathrm{~nm}$ and expressed as rutin equivalents $\left(\mathrm{RE} \mathrm{g}^{-1}\right)$. Anthocyanins [(range: 515$545 \mathrm{~nm}$ (band I) and 275-285 nm (band II)] quantified at $520 \mathrm{~nm}$ and expressed as cyanidin-3-glucoside equivalents $\left(\mathrm{Cn} 3 \mathrm{GE} \mathrm{g}^{-1}\right)$. The concentration of flavonoid derivatives in studied Brassica vegetables is presented in Table 1. It was evident that only PMF was found in broccoli, and Brussels sprouts, whereas none of the other categories were observed in any of studied vegetables. Methanol was found to be the optimum solvent for the extraction of PMF from Brassica vegetables.

Overall, considerable variations in the type of PPs were found among vegetables. These results show a clear ranking order, in terms of phenolic content, which was broccoli greater than Brussels sprouts and greater than white cabbage.

\section{Antioxidant capacity analysis}

2-Diphenyl-1-picrylhydrazyl free radical scavenging capacity All the vegetable extracts and reference compound (ascorbic acid) at the tested concentration were capable of directly reacting with and quenching DPPH radical (Table 2). In the case of broccoli, methanolic extract was found to have the highest DPPH radical-scavenging capacity with $\mathrm{EC}_{50} 0.71 \pm 0.06 \mathrm{mg} \mathrm{mL}^{-1}$ of extract. As compared to methanol, ethanol and acetone extracts showed $39 \%$ and $47 \%$ lesser scavenging capacities, respectively. A similar trend was observed for white cabbage and broccoli also, where methanolic extract showed the highest scavenging capacity for DPPH radical. The results from the present study were in agreement with the previous reports that indicate methanolic extracts to have higher DPPH radical scavenging capacity than acetone extracts (Sun et al., 2007). Among the vegetables studied, broccoli was found to have $11 \%$ and $30 \%$ higher DPPH radicalscavenging capacity in comparison with Brussels sprouts and white cabbage, respectively. 
(a)

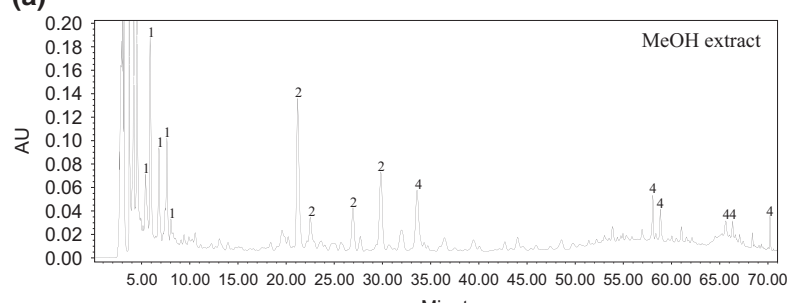
Minutes
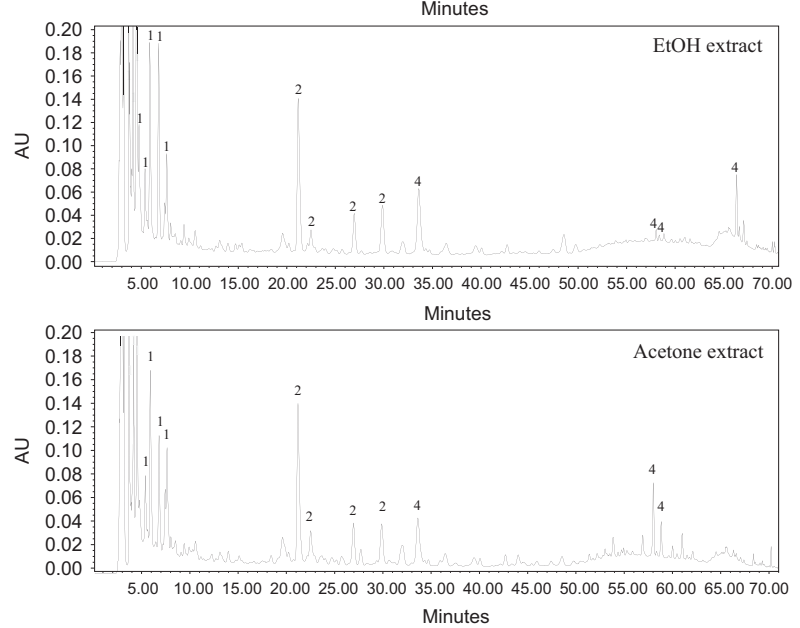

(c)
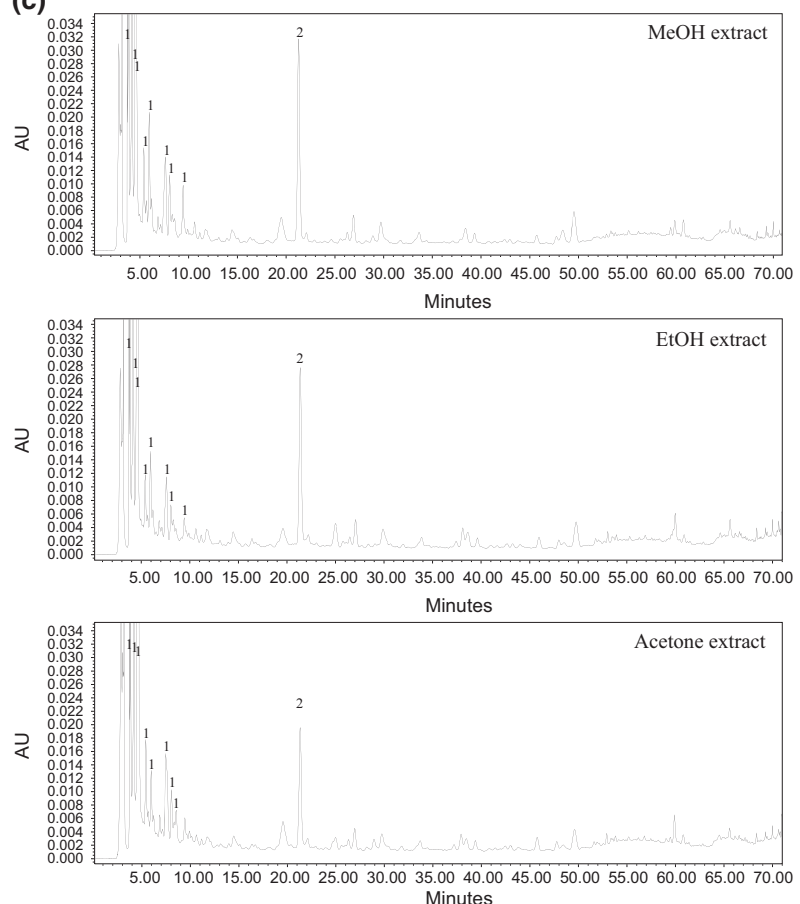

(b)

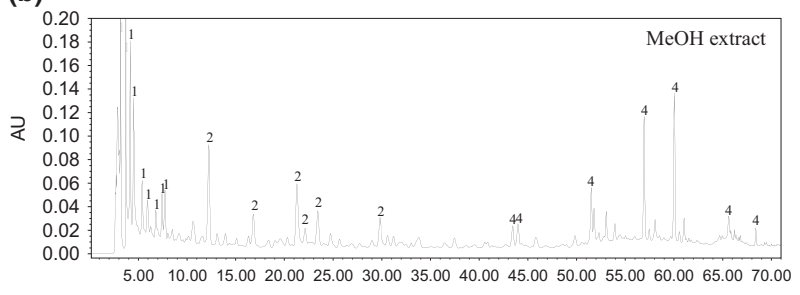
Minutes

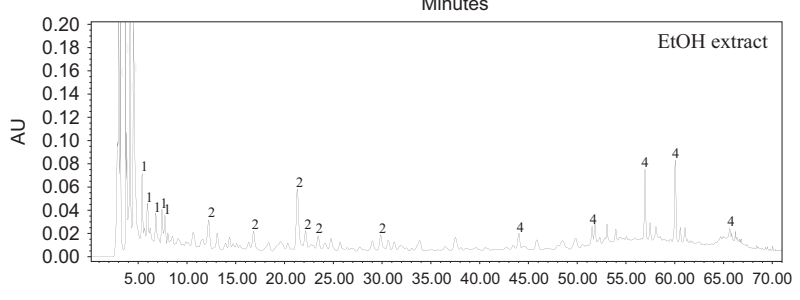
Minutes

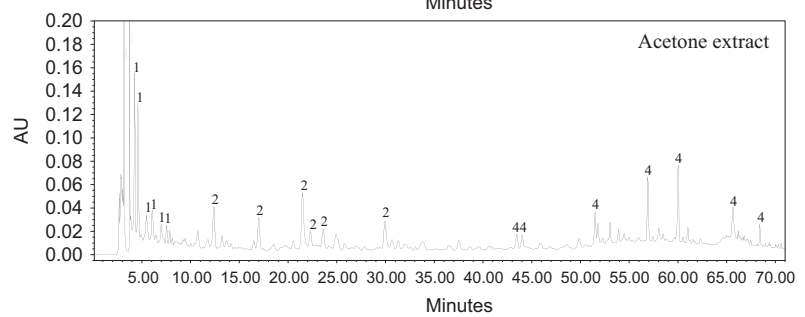

Figure 1 A comparative high-performance liquid chromatography coupled with diode array detector (HPLC-DAD) profile at 280 nm for (a) broccoli, (b) Brussels sprouts and (c) white cabbage extracted with different solvents [1-hydroxybenzoic acid derivatives; 2-hydroxycinnamic acid derivatives; 3-flavones; 4-polymethoxylated flavonoid]. 
Table 2 Comparative study of antioxidant capacity (expressed as $\mathrm{EC}_{50}$ values) of different Brassica vegetables (broccoli, Brussels sprouts and white cabbage) extracted with different solvent system (methanol, ethanol and acetone) and reference antioxidant compounds

\begin{tabular}{|c|c|c|c|c|c|}
\hline Extraction solvent & DPPH & LPO & FIC & $\mathrm{H}_{2} \mathrm{O}_{2}$ & FRAP \\
\hline \multicolumn{6}{|l|}{ Broccoli } \\
\hline $60 \%$ Methanol & $0.71 \pm 0.06^{a}$ & $6.25 \pm 0.39^{a}$ & $1.58 \pm 0.10^{\mathrm{a}}$ & $1.29 \pm 0.10^{\mathrm{a}}$ & $4.66 \pm 0.06^{\mathrm{a}}$ \\
\hline $60 \%$ Ethanol & $1.16 \pm 0.07^{b}$ & $6.92 \pm 0.97^{a}$ & $2.04 \pm 0.11^{b}$ & $1.77 \pm 0.16^{b}$ & $3.68 \pm 0.03^{b}$ \\
\hline $60 \%$ Acetone & $1.35 \pm 0.13^{b}$ & $8.20 \pm 0.13^{b}$ & $2.16 \pm 0.25^{b}$ & $2.17 \pm 0.13^{\mathrm{c}}$ & $2.79 \pm 0.23^{c}$ \\
\hline \multicolumn{6}{|l|}{ Brussels sprouts } \\
\hline $60 \%$ Methanol & $0.80 \pm 0.09^{a}$ & $5.90 \pm 0.22^{\mathrm{a}}$ & $2.14 \pm 0.36^{a}$ & $2.14 \pm 0.02^{\mathrm{a}}$ & $5.11 \pm 0.07^{\mathrm{a}}$ \\
\hline $60 \%$ Ethanol & $0.98 \pm 0.05^{\mathrm{a}}$ & $8.85 \pm 0.14^{b}$ & $3.97 \pm 0.22^{b}$ & $3.95 \pm 0.08^{b}$ & $4.37 \pm 0.35^{b}$ \\
\hline $60 \%$ Acetone & $1.22 \pm 0.06^{b}$ & $10.6 \pm 0.69^{c}$ & $4.29 \pm 0.57^{b}$ & $5.41 \pm 0.21^{\mathrm{c}}$ & $4.29 \pm 0.14^{b}$ \\
\hline \multicolumn{6}{|l|}{ White cabbage } \\
\hline $60 \%$ Methanol & $1.01 \pm 0.03^{a}$ & $9.58 \pm 0.12^{\mathrm{a}}$ & $3.45 \pm 0.37^{a}$ & $2.84 \pm 0.21^{a}$ & $5.85 \pm 0.08^{a}$ \\
\hline $60 \%$ Ethanol & $1.16 \pm 0.15^{\mathrm{a}}$ & $10.8 \pm 0.16^{b}$ & $3.89 \pm 0.24^{a}$ & $4.04 \pm 0.06^{b}$ & $5.18 \pm 0.36^{b}$ \\
\hline $60 \%$ Acetone & $1.40 \pm 0.17^{\mathrm{b}}$ & $11.8 \pm 0.70^{\mathrm{C}}$ & $4.72 \pm 0.30^{b}$ & $5.93 \pm 0.31^{\mathrm{c}}$ & $4.60 \pm 0.05^{c}$ \\
\hline \multicolumn{6}{|l|}{ Reference } \\
\hline Ascorbic acid & $0.02 \pm 0.00$ & $0.09 \pm 0.00$ & - & - & - \\
\hline EDTA & - & - & $0.02 \pm 0.00$ & - & - \\
\hline BHT & - & - & - & $0.17 \pm 0.03$ & - \\
\hline
\end{tabular}

*Data are expressed as mean $\pm \mathrm{SD}(n=6)$.

$\mathrm{DPPH}, 2$-diphenyl-1-picrylhydrazyl free radical scavenging capacity; FRAP, ferric ion reducing antioxidant potential assay; LPO, lipid peroxidation in a haemoglobin-induced linoleic acid system; FIC, ferrous ion-chelating capacity; $\mathrm{H}_{2} \mathrm{O}_{2}$, hydrogen peroxide scavenging assay; BHT, butylated hydroxytoluene; EDTA, ethylenediaminetetraacetic acid; -, not applied.

Means not sharing the same letter are significantly different (LSD) at $P<0.05$ probability level in each row for different solvent extracts of individual species.

\section{Lipid peroxidation in a haemoglobin-induced linoleic acid system}

The LPO capacity of vegetable extracts in terms of $\mathrm{EC}_{50}$ 4 value is shown in Table 2 . All the vegetable extracts and reference compound (ascorbic acid) showed a concentration-dependent LPO inhibitory ability, and significant differences $(P<0.05)$ were observed among all the vegetables and their ascorbic acid content. Methanolic extract showed the higher inhibitory ability on lipid oxidation for all the vegetables. For broccoli, methanolic extracts had $10 \%$ and $24 \%$ higher inhibitory ability than ethanolic and acetone extracts, respectively. A similar trend was observed for Brussels sprouts where the methanolic extract was $33 \%$ and $44 \%$ more inhibitory than ethanolic and acetone extracts, respectively, whereas white cabbage had $11 \%$ and $19 \%$ higher inhibitory ability than ethanolic and acetone extracts, respectively. Among the vegetables studied, Brussels sprouts extract was superior in LPO followed by broccoli, and the lowest was white cabbage. In contrast to the results reported by Kuda et al. (2005) on edible algae, phenolic compounds from studied Brassica vegetables showed almost twofold higher inhibitory capacity for LPO.

\section{Ferrous ion-chelating capacity}

Ferrous ion-chelating capacity of different solvent extracts of broccoli, Brussels sprouts, white cabbage and EDTA are shown in Table 2. As can be seen, all the vegetable extract had significant metal-chelating capacity in different proportion. Methanolic extracts of broccoli, Brussels sprouts and white cabbage showed significantly $(P<0.05)$ higher metal-chelating capacity in comparison with the other solvent extracts. Significant difference in the activity, in increasing order of acetone $<$ ethanol $<$ methanol, was found among all the vegetable samples. Among all the vegetables studied, the highest $\mathrm{Fe}^{2+}$-chelating activity was found in broccoli followed by Brussels sprouts, and the lowest activity was found in white cabbage. The metal-chelating effects of all the vegetable extracts and EDTA were concentration dependent (not shown).

\section{Hydrogen peroxide scavenging capacity}

All the vegetable extracts and reference compound potently scavenged $\mathrm{H}_{2} \mathrm{O}_{2}$ in a dose-dependent manner (not shown; Table 2). In the case of Broccoli, methanolic extract was found to have the highest $\mathrm{H}_{2} \mathrm{O}_{2}$ radical scavenging capacity with $\mathrm{EC}_{50} 1.29 \pm 0.10 \mathrm{mg} \mathrm{mL}^{-1}$ of extract. As compared to methanol, ethanol and acetone extracts showed $27 \%$ and $40 \%$ lesser scavenging capacities, respectively. A similar trend was observed for the other vegetables wherein methanolic extract showed the highest scavenging capacity for $\mathrm{H}_{2} \mathrm{O}_{2}$ radical with $\mathrm{EC}_{50}$ $2.14 \pm 0.02$ and $2.84 \pm 0.21 \mathrm{mg} \mathrm{mL}^{-1}$ of extract for white cabbage and Brussels sprouts, respectively. It appeared that among the vegetable extract, broccoli had a stronger $\mathrm{H}_{2} \mathrm{O}_{2}$-scavenging capacity followed by Brus- 
sels sprouts and white cabbage. On the other hand, BHT had significantly higher $\mathrm{H}_{2} \mathrm{O}_{2}$ scavenging capacity compared with other vegetable extracts tested ranging from 6 to 20 times.

Ferric ion reducing antioxidant potential assay

The experimental results (Table 2) collected in the present study indicate that different solvent extracts of vegetables had the ability to reduce $\mathrm{Fe}^{3+}$ to $\mathrm{Fe}^{2+}$ in different proportions. It showed that methanolic extract had relatively strong ferric ion reducing capacities compared with those of ethanol and acetone extracts. Reducing capacity of methanolic extract of broccoli was 1.3 and 1.7 times higher than those of ethanol and acetone extracts, respectively. A similar trend was observed for Brussels sprouts and white cabbage. Among all the vegetables, white cabbage had the highest reducing capacity followed by Brussels sprouts and broccoli, which were $13 \%$ and $20 \%$ lower than that of white cabbage.

\section{Antibacterial activity}

Many naturally occurring plants, including vegetables, have been shown to possess antibacterial activity and serve as a source of antibacterial agents against foodborne and food spoilage bacteria (Ali et al., 2001; Hu et al., 2004; Ayaz et al., 2008). In the present study, four different organisms were selected to check the antibacterial efficacy of vegetable extracts. The selection of the pathogenic microbes (L. monocytogenes and S. abony) was made after discussions with the Food Safety Authority of Ireland (FSAI) as these were found to be the most challenging organisms for the safety of food products in Ireland. The other two (E. faecalis and $P$. aeruginosa) are the most widespread food spoilage microorganisms.

In the present study, a range of concentrations $(2.8 \%$, $1.4 \%, 0.7 \%, 0.35 \%, 0.17 \%$ and $0.09 \%$ ) of vegetable extracts were checked for their antibacterial activity against all the selected bacteria. Table 3 shows a comparative study of antibacterial activities of broccoli, Brussels sprouts and white cabbage extracts with SB and SN against L. monocytogenes, $P$. aeruginosa, S. abony and $E$. faecalis at a concentration of $2.8 \%$. Regardless of the organism, all the vegetable extracts exhibited weak to moderate activity against the tested bacteria. Among the vegetables, broccoli extract showed the highest antibacterial activity against most of the tested bacteria in comparison with Brussels sprouts and white cabbage. Resistance to the extracts was not correlated with taxonomy, as L. monocytogenes (Gram-positive), $S$. abony and P. aeruginosa (Gram-negative) were the most sensitive followed by E. faecalis which was the most resistant.

Antibacterial activities of vegetable extracts were also compared with synthetic antibacterial agents such as SB
Table 3 Comparative study of antibacterial activities of broccoli, Brussels sprouts and white cabbage extracts with sodium benzoate (SB) and sodium nitrite (SN) against Listeria monocytogenes, Pseudomonas aeruginosa, Salmonella abony and Enterococcus faecalis (all the values are means \pm SD of three parallel experiments in duplicate)

\begin{tabular}{lllll}
\hline \multirow{3}{*}{$\begin{array}{llll}\text { Extraction } \\
\text { solvent }\end{array}$} & \multicolumn{2}{l}{ Lest bacteria } & & \\
\cline { 2 - 5 } & Lonocytogenes & S. abony & E. faecalis & P. aeruginosa \\
\hline Broccoli & & & & \\
$\mathrm{MeOH}$ & ++ & ++ & + & ++ \\
$\mathrm{EtOH}$ & ++ & ++ & + & ++ \\
Acetone & ++ & ++ & + & ++ \\
Brussels sprouts & & & \\
$\mathrm{MeOH}$ & + & + & + & ++ \\
EtOH & + & + & + & ++ \\
$\mathrm{Acetone}$ & + & + & + & ++ \\
White cabbage & & & \\
$\mathrm{MeOH}$ & + & + & + & + \\
EtOH & + & + & + & + \\
$\mathrm{Acetone}$ & + & + & + & + \\
$\mathrm{SB}$ & ++++ & ++ & + & ++ \\
$\mathrm{SN}$ & ++++ & ++ & ++ & ++++ \\
\hline
\end{tabular}

,$+<50$ weak; ++, 50-90 moderate; +++, 90-97 strong; ++++, 97-100 very strong (Cox et al., 2010).

and SN. All the studied vegetable extracts showed lower inhibition in comparison with SB and SN. In the case of L. monocytogenes, inhibition ranges from $51.1 \%$ to $69.1 \%$ for broccoli, $33.3 \%$ to $39.1 \%$ for Brussels sprouts and $23.2 \%$ to $34.0 \%$ for white cabbage, which were $28-65 \%$ lower than that of the SB and $30-66 \%$ than SN. Similar trend was observed against S. abony inhibition that ranges from $50.4 \%$ to $57.3 \%$ for broccoli, $27.7 \%$ to $38.1 \%$ for Brussels sprouts and $24.3 \%$ to $34.7 \%$ for white cabbage, which were $16-50 \%$ lesser than SB and 33-60\% than SN. The antibacterial activity against $P$. aeruginosa varied from $37.6 \%$ to $49.8 \%$ for broccoli, $26.8 \%$ to $39.0 \%$ for Brussels sprouts and $20.1 \%$ to $28.2 \%$ for white cabbage, which were $41-66 \%$ fewer than SB and $50-72 \%$ than $\mathrm{SN}$, whereas antibacterial activity against $E$. faecalis inhibition varied from $23.0 \%$ to $25.4 \%$ for broccoli, 15.2 $23.8 \%$ for Brussels sprouts and $13.2-17.7 \%$ for white cabbage, which were $36-55 \%$ lesser as compare to SB and $61-72 \%$ compare to $\mathrm{SN}$.

\section{Conclusion}

This work demonstrates that the type of extraction solvent had a substantial influence on the phytochemical contents, antioxidant capacity and antibacterial activity. This study also indicates that methanol is the most efficient solvent for the extraction of polyphenolic compounds from these vegetables. The present findings suggest that there may be a potential to utilise such 
vegetable extracts in food products with the aim of enhancing the quality and nutritive value of foods. Further investigations are required for identifying and quantifying individual polyphenolic compounds and the analysis of their antioxidant and antibacterial properties in vivo.

\section{Acknowledgments}

The authors acknowledge funding from the Irish government under the Technological Sector Research Scheme (Strand III) of the National Development Plan.

\section{References}

Abas, F., Lajis, N.H., Israf, D.A., Khozirah, S. \& Umi Kalsom, Y. (2006). Antioxidant and nitric oxide inhibition activities of selected Malay traditional vegetables. Food Chemistry, 95, 566-573.

Ali, Y., Mavi, A. \& Kara, A.A. (2001). Determination of antioxidant and antimicrobial activities of Rumex crispus L. extracts. Journal of Agricultural and Food Chemistry, 49, 4083-4089.

Andarwulan, N., Batari, R., Sandrasari, D.A., Bolling, B. \& Wijaya, H. (2010). Flavonoid content and antioxidant activity of vegetables from Indonesia. Food Chemistry, 121, 1231-1235.

Ayaz, F.A., Hayırloglu-Ayaz, S., Alpay-Karaoglu, S. et al. (2008). Phenolic acid contents of kale (Brassica oleraceae L. var. acephala DC.) extracts and their antioxidant and antibacterial activities. Food Chemistry, 107, 19-25.

Botterweck, A.A.M., Verhagen, H., Goldbohm, R.A., Kleinjans, J. \& van den Brandt, P.A. (2000). Intake of butylated hydroxyanisole and butylated hydroxytoluene and stomach cancer risk: results from analyses in the Netherlands Cohort Study. Food and Chemical Toxicology, 38, 599-605.

Bravo, L. (1998). Polyphenols: chemistry, dietary sources, metabolism, and nutritional significance. Nutrition Reviews, 56, 317-333.

Clifford, M.N. (2000). Chlorogenic acids and other cinnamates nature, occurrence, dietary burden, absorption and metabolism. Journal of the Science of Food and Agriculture, 80, 1033-1043.

Cook, N.C. \& Samman, S. (1996). Flavonoids - Chemistry, metabolism, cardioprotective effects, and dietary sources. The Journal of

5 Nutritional Biochemistry, 7, 66-76.

Cox, S., Abu-Ghannam, N. \& Gupta, S. (2010). An assessment of the antioxidant and antimicrobial activity of six species of edible Irish seaweeds. International Food Research Journal, 17, 205-220.

Ganesan, P., Kumar, C.S. \& Bhaskar, N. (2008). Antioxidant properties of methanol extract and its solvent fractions obtained from selected Indian red seaweeds. Bioresource Technology, 99, 2717-2723.

Halliwell, B. (1994). Free radicals, antioxidants, and human disease: curiosity, cause, or consequence? The Lancet, 344, 721-724.

Hu, S.H., Wang, J.C., Kung, H.F., Wang, J.T., Lee, W.L. \& Yang, Y.H. (2004). Antimicrobial effect of extracts of Cruciferous vegetables. The Kaohsiung Journal of Medical Sciences, 20, 591-599.

Isabelle, M., Lee, B.L., Lim, M.T., Koh, W.P., Huang, D. \& Ong, C.N. (2010). Antioxidant activity and profiles of common vegetables in Singapore. Food Chemistry, 120, 993-1003.

Jaiswal, A.K., Rajauria, G., Abu-Ghannam, N. \& Gupta, S. (2011a). Effect of different solvents on polyphenolic content, antioxidant capacity and antibacterial activity of Irish York cabbage. Journal of Food Biochemistry, ???, ????-????. doi: 10.1111/j.1745-4514.2011.

6 00545.x.
Jaiswal, A.K., Gupta, S., Abu-Ghannam, N. \& Cox, S. (2011b). Application of Baranyi function to model the antimicrobial properties of solvent extract from Irish York cabbage against food spoilage and pathogenic bacteria. Food Science and Technology International, ????, ????-????. doi: 10.1177/1082013210399667.

Kim, D.O., Padilla-Zakour, O.I. \& Griffiths, P.D. (2004). Flavonoids and antioxidant capacity of various cabbage genotypes at juvenile stage. Journal of Food Science, 69, C685-C689.

Kuda, T., Tsunekawa, M., Goto, H. \& Araki, Y. (2005). Antioxidant properties of four edible algae harvested in the Noto Peninsula, Japan. Journal of Food Composition and Analysis, 18, 625-633.

Kyung, K.H. \& Fleming, H.P. (1994). S-Methyl-L-Cysteine sulfoxide as the precursor of methyl methanethiolsulfinate, the principal antibacterial compound in cabbage. Journal of Food Science, 59, $350-355$.

Lin, J.Y. \& Tang, C.Y. (2007). Determination of total phenolic and flavonoid contents in selected fruits and vegetables, as well as their stimulatory effects on mouse splenocyte proliferation. Food Chemistry, 101, 140-147.

Liu, Q. \& Yao, H. (2007). Antioxidant activities of barley seeds extracts. Food Chemistry, 102, 732-737.

Liu, S.C., Lin, J.T., Wang, C.K., Chen, H.Y. \& Yang, D.J. (2009). Antioxidant properties of various solvent extracts from lychee (Litchi chinenesis Sonn.) flowers. Food Chemistry, 114, 577-581.

March, R. \& Brodbelt, J. (2008). Analysis of flavonoids: tandem mass spectrometry, computational methods, and NMR. Journal of Mass Spectrometry, 43, 1581-1617.

Pantelidis, G.E., Vasilakakis, M., Manganaris, G.A. \& Diamantidis, G. (2007). Antioxidant capacity, phenol, anthocyanin and ascorbic acid contents in raspberries, blackberries, red currants, gooseberries and cornelian cherries. Food Chemistry, 102, 777-783.

Podsędek, A. (2007). Natural antioxidants and antioxidant capacity of Brassica vegetables: a review. LWT-Food Science and Technology, 40, 1-11.

Podsędek, A., Sosnowska, D., Redzynia, M. \& Anders, B. (2006). Antioxidant capacity and content of Brassica oleracea dietary antioxidants. International Journal of Food Science and Technology, 41, 49-58.

Rajauria, G., Jaiswal, A.K., Abu-Ghannam, N. \& Gupta, S. (2010). Effect of hydrothermal processing on colour, antioxidant and free radical scavenging capacities of edible Irish brown seaweeds. International Journal of Food Science and Technology, 45, 24852493.

Rao, A.R., Sarada, R., Baskaran, V. \& Ravishankar, G.A. (2006). Antioxidant activity of Botryococcus braunii extract elucidated in vitro models. Journal of Agricultural and Food Chemistry, 54, 45934599.

Sreeramulu, D. \& Raghunath, M. (2010). Antioxidant activity and phenolic content of roots, tubers and vegetables commonly consumed in India. Food Research International, 43, 1017-1020.

Sun, T. \& Ho, C.T. (2005). Antioxidant activities of buckwheat extracts. Food Chemistry, 90, 743-749.

Sun, T., Powers, J.R. \& Tang, J. (2007). Evaluation of the antioxidant activity of asparagus, broccoli and their juices. Food Chemistry, 105, 101-106.

Wijngaard, H.H., Rößle, C. \& Brunton, N. (2009). A survey of Irish fruit and vegetable waste and by-products as a source of polyphenolic antioxidants. Food Chemistry, 116, 202-207.

Zhao, B. \& Hall, C.A. III (2008). Composition and antioxidant activity of raisin extracts obtained from various solvents. Food Chemistry, 108, 511-518.

Zhou, K. \& Yu, L. (2006). Total phenolic contents and antioxidant properties of commonly consumed vegetables grown in Colorado. LWT-Food Science and Technology, 39, 1155-1162. 